\title{
Effect of friction on the contact stress of a coated polymer gear
}

\author{
Su-Min BAE, Kuk-Jin SEO, Dae-Eun KIM* \\ Department of Mechanical Engineering, Yonsei University, Seoul 03722, Republic of Korea \\ Received: 31 August 2019 / Revised: 20 December 2019 / Accepted: 04 January 2020 \\ (C) The author(s) 2020 .
}

\begin{abstract}
Polymer gears are used extensively in various applications. However, durability issues have been emerging because of friction at gear tooth contact areas. To extend the lifetime of polymer gears, a low-frictional coating has been considered as a possible strategy. In this study, a finite element simulation method was performed to investigate the contact stress between a pair of coated polymer gears. The simulation included various friction coefficients (COFs) for studying the effects of friction during the operation. Numerical results revealed that the friction causes the contact stress to shift over the roll angle, which is attributed to the direction of the sliding friction based on a free-body diagram. We also investigated the effects of coating and found that a thin coating has little effect on the bulk deformation behavior of the gear. Moreover, the stress distribution in the coating at the pitch point was investigated as the COF increased. Under zero friction, three notable stress regions were observed: 1) the center of the surface, 2) the end of the contact, and 3) the overall contact area. As COF was increased in the micro-slip region of the contact interface, both tensile and compressive stresses in the coating increased. This study provides significant aid to engineers for understanding the stress response of the coating applied to polymer gears to achieve an optimal design.
\end{abstract}

Keywords: coating; contact stress; finite element method (FEM); friction; polymer gear

\section{Introduction}

The weight reduction of mechanical components is a crucial requirement for reducing energy consumption and satisfying environmental regulations [1-3]. In response to these global trends, polymer gears have been gaining attention in various applications [4-6]. In the automotive industry, the demand for polymer gears has steadily been increasing as a means of replacing metallic gears to improve efficiency [5]. The benefits of polymer gears include low production costs, low inertia, high corrosion resistance, and the ability to be operated without a lubricant [4, 7].

One challenging aspect of employing polymer gears is the friction between mating gears, which is highly detrimental to the lifetime of the polymer gear [6]. As more contact stress is applied to the gear teeth, the running temperature increases because of the friction [8]. The heat generated by the friction accumulates at the surface because the polymer has poor thermal conductivity [9]. Consequently, the material softens and severe surface wear occurs [10].

A general method to reduce the friction in mating gears is the use of lubricants or applying lowfrictional coatings [11]. Polymer gears are often used in applications in which lubricants cannot be used, such as food processing machines and office equipment [12]. Therefore, the application of lowfrictional coatings is an appropriate approach for

* Corresponding author: Dae-Eun Kim, E-mail: kimde@yonsei.ac.kr 
reducing the friction between the polymer gear teeth. Benefits of the low-frictional coatings include: (1) modification of only the surface properties while maintaining the bulk responses of the substrate [13], (2) improvement of efficiency by reducing the frictional loss in the mechanical systems [14], and (3) the efficient usage of resources because of the small amount of coating material required for application [15]. The feasibility of applying a lowfrictional coating to polymer gears has been verified by Dearn et al. [7], who investigated the effects of four different coatings on polymer gears. One of the coatings is polytetrafluoroethylene (PTFE), which is known for its low-friction property. Experimental results revealed that the running temperature and wear were significantly reduced by applying a PTFE coating. However, when the PTFE coating was applied to a hard-composite polymer gear, the coating was easily scratched, and wear increased rapidly because the coating was softer than the gear.

Generally, low-frictional coatings should simultaneously satisfy properties such as high hardness, high stiffness, superior wear resistance, and sufficient adhesion to the substrate [16]. Diamond-like carbon (DLC) not only has the properties that low-frictional coatings should provide, but also has good mass productivity, attracting special attention in various industries [17]. Notably, DLC shows both chemical inertness and a low friction coefficient (COF, even in dry conditions), which makes it a potential candidate for polymer gears $[18,19]$. Because of the intrinsic properties, various experimental studies on polymer substrates have demonstrated that DLC provides a significant improvement by reducing the friction and wear while supporting high contact pressure of up to $350 \mathrm{MPa}$, which is a relatively harsh condition for polymeric materials [20, 21].

However, hard coatings on soft substrates (such as DLC on polymers) may encounter the challenge of having significant differences in their mechanical properties. When a coating/substrate system with a high elastic modulus mismatch is subjected to a load, stress concentration occurs at the interface, which increases the probability of delamination between the coating and the substrate [22]. Therefore, it is necessary to evaluate the contact stress response of coated polymer gears to predict undesirable failures caused by the contact stress during operation. However, a fundamental study on the contact stress during the operation of a coated polymer gear considering friction is still lacking.

Rating standards, such as those used by the International Standards Organization (ISO) and the American Gear Manufacturers Association (AGMA), are often used to calculate the contact stress of gears in the industry [23, 24]. As described in Section 2.1, these rating standards provide an estimation of the contact stress at the pitch point $[25,26]$. These standards result in valid estimations for metallic gears because they are based on rigid body motions [25]. However, the action of involute gears subjected to a load cannot be considered as a conjugate action because of tooth deformation [27]. Polymers have a significantly lower elastic modulus than metals; thus, deflections of gear teeth must be considered to obtain an accurate estimation [25]. Another limitation is that the standards do not consider friction effects when evaluating the contact stress [24]. Moreover, the existing standards cannot account for evaluating gears with a coating. Various studies have used the finite element method (FEM) to understand the contact stress response of mechanical systems with a coating [22, 28-30]. The advantages of FEM are that deformation can be considered in the simulation, leading to more accurate results [31], and friction can be included in the contact problem [24].

In this study, the FEM model was developed to investigate the contact stress response of coated polymer gears with the frictional effect during gear operation. Two-dimensional simulations using quasistatic analysis were performed for involute spur gears. Contact stress results were obtained for a complete mesh cycle between a pair of gear teeth. Simulation results were compared with those predicted by the international rating standards. Furthermore, stress analysis of the coating was performed at the pitch point with a range of COF values.

\section{Contact stress calculation methods}

\subsection{International rating standards}

Rating standards such as AGMA and ISO, which 
are based on the Hertzian contact theory, have been used to evaluate the contact stress with the assumption that the sliding friction and tooth deflection are negligible $[23,24]$. In these standards, the maximum contact pressure at the pitch point can be calculated by using the transmitted load, face width, material properties, and several factors that affect the operating environment of the gear $[25,26]$.

The maximum contact pressure, $\sigma_{H}$, of AGMA is given as follows:

$$
\sigma_{H}=Z_{\mathrm{e}} \sqrt{F_{\mathrm{t}} K_{\mathrm{o}} K_{\mathrm{d}} K_{\mathrm{s}} \frac{K_{1}}{d_{\mathrm{p}} b Z_{\mathrm{g}}}}
$$

where subscripts $\mathrm{o}, \mathrm{d}, \mathrm{s}$, and 1 represent overload, dynamic, size, and load distribution factors of $K$, respectively. $Z_{\mathrm{e}}$ is the elastic coefficient, $Z_{\mathrm{g}}$ is the geometry coefficient, $F_{\mathrm{t}}$ is the tangential load applied on a gear tooth, $d_{\mathrm{p}}$ is the pitch diameter of the pinion gear, and $b$ is the face width [24].

$\sigma_{H}$ of ISO 6336 is given as follows:

$$
\sigma_{H}=Z_{\mathrm{s}} Z_{\mathrm{z}} Z_{\mathrm{e}} Z_{\mathrm{c}} \sqrt{K_{\mathrm{a}} K_{d} K_{\mathrm{t}} K_{\mathrm{f}} \frac{F_{\mathrm{t}}}{d_{\mathrm{p}} b} \frac{u+1}{u}}
$$

where $K_{\mathrm{a}}, K_{\mathrm{t}}$, and $K_{\mathrm{f}}$ are the application, transverse load, and face load factors, respectively. $u$ is the gear ratio; subscripts $s, z$, and $c$ represent the single pair tooth contact, zone, and contact ratio factors of $Z$, respectively [32].

\subsection{Quasi-static FEM}

The study focuses on the contact stress analysis of gear sets during operation. For this purpose, an analysis is required for all contact positions along the line of action. The quasi-static analysis is an effective method to calculate the stress for the contact positions. Although the inertia effect is neglected, it is relatively low during polymer gear operation. Moreover, quasi-static analysis reduces the computation time because the model is more straightforward than that of dynamic analysis [26]. The governing equation of the quasi-static model in the matrix form can be obtained by the following dynamic model:

$$
[\boldsymbol{M}]\{\ddot{\boldsymbol{u}}\}+[\boldsymbol{C}]\{\dot{\boldsymbol{u}}\}+[\boldsymbol{K}]\{\boldsymbol{u}\}=\{\boldsymbol{F}(\boldsymbol{t})\}
$$

where $\{\ddot{\boldsymbol{u}}\},\{\dot{\boldsymbol{u}}\},\{\boldsymbol{u}\}$, and $\{\boldsymbol{F}(t)\}$ are the nodal acceleration, velocity, displacement vectors, and the total external force vector applied in the system, respectively. $[\boldsymbol{M}]$ represents the matrix of mass, $[\boldsymbol{C}]$ is the matrix of constant damping, and $[\boldsymbol{K}]$ is the matrix of stiffness. By considering the system as a quasi-static condition, the terms for velocity and acceleration, which are inertia effects, are ignored. Hence, Eq. (3) can be rewritten as the following:

$$
[\boldsymbol{K}]\{\boldsymbol{u}\}=\{\boldsymbol{F}\}
$$

\section{Simulation}

\subsection{Gear geometry and material properties}

The following basic parameters were used to generate the involute spur gear model: pressure angle, $20^{\circ}$; module, $1.5 \mathrm{~mm}$; and the number of teeth, 30 . Additionally, a tip relief radius of $0.2 \mathrm{~mm}$ was applied to the tooth profile to eliminate unnecessary stress peaks that occur at the start and the end of contact [26]. A polyether ether ketone (PEEK) composite polymer and DLC were chosen as the gear and coating material, respectively, to investigate the contact stress of a hard coating applied to a polymer gear. The material properties used in the simulation were obtained from Refs. [30, 33]. The material properties of the PEEK composite polymer are an elastic modulus of $28 \mathrm{GPa}$ and a Poisson's ratio of 0.44 . For DLC, an elastic modulus of 170 GPa and a Poisson's ratio of 0.2 were used as input values. The thickness of the coating was set to $2 \mu \mathrm{m}$, which was chosen based on previous studies that used DLC to improve the tribological properties of gears [19, 34, 35]. A summary of the geometric parameters and material information is shown in Table 1. All materials used in this study are assumed perfectly elastic and homogeneous.

\subsection{Simulation model and mesh}

All simulations were performed using commercial FEM software (ABAQUS, version 6.11). Only five teeth were modeled for each driving and pinion gear to reduce the computation time. Both the coating and the gear were assumed to have perfect adhesion. For a more accurate calculation, one pair of gear teeth was densely discretized, as shown in Fig. 1. 
Table 1 Geometric parameters of the involute spur gear and material information.

\begin{tabular}{cccc}
\hline Parameter & Driving and pinion gear & Material information \\
\hline Module $(\mathrm{mm})$ & 1.5 & Elastic modulus of gear pair $(\mathrm{GPa})$ & 28 \\
Number of teeth & 30 & Poisson's ratio of gear pair & 0.44 \\
Pressure angle $\left({ }^{\circ}\right)$ & 20 & Elastic modulus of coating $(\mathrm{GPa})$ & 170 \\
Center distance $(\mathrm{mm})$ & 45 & Poisson's ratio of coating & 0.2 \\
Tip relief $(\mathrm{mm})$ & 0.2 (Radius) & Thickness of coating $(\mu \mathrm{m})$ & 2 \\
\hline
\end{tabular}

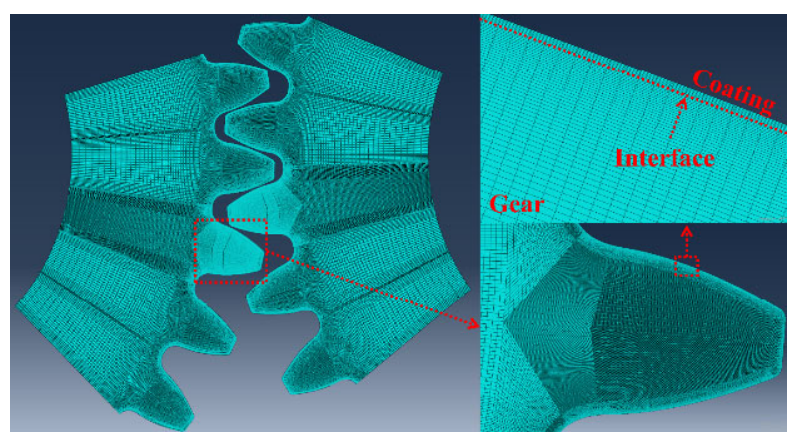

Fig. 1 Assembled gear set with densely discretized pair of gear teeth.

The four other pairs were discretized with a relatively low density to avoid excessive and unnecessary computation time.

A quadratic plane strain mesh was used, termed "CPE4" in ABAQUS. The total number of meshes for the uncoated gear set is 604,876 , and the total for the coated gear set is 626,166 . The contact pairs were defined by considering the driving and pinion gear flanks as master and slave surfaces, respectively. The master nodes may penetrate the slave surface, but the slave nodes cannot penetrate the master surface. To apply a COF, Coulomb friction was considered to be on the entire surface where contact occurs. It should be mentioned that this COF was applied to represent the micro-slip phenomenon that occurs at the contact region. Therefore, the COF value at the micro-slip region would be significantly higher than the COF of the overall rolling motion of the gear. Essentially, the shear stress generated at the contact region was dictated by the magnitude of the $\mathrm{COF}$ at the micro-slip region. COFs were obtained from previous experimental studies, the maximum of which was 0.5 for bare PEEK composites and 0.15 for coated PEEK composite gear sets [17, 36]. Therefore, COFs of $0.1,0.3$, and 0.5 were chosen for the bare polymer gear sets, and $0.05,0.1$, and 0.15 for the coated gear sets. The following additional assumptions were made to simplify the simulation: 1) no heat-related stress, 2) no roughness effect, 3) no misalignment, and 4) no residual stress within the coating.

\subsection{Boundary conditions}

Two reference points were created at the center of the driving and pinion gears, respectively, to apply the boundary conditions. Coupling constraints were used to join the reference points and the inner surface of the gears. The boundary conditions were applied sequentially with the following steps:

1) Approaching step: the center of the driving gear was constrained in a rotational direction. The pinion gear rotated until it contacted the driving gear.

2) Loading step: a loading torque of $5 \mathrm{~N} \cdot \mathrm{m}$ was applied to the reference point of the pinion gear while the driving gear was constrained in the rotational direction.

3) Rotation step: a rotation was applied to the center of the driving gear after the central constraint was removed.

\section{Results and discussion}

\subsection{Contact stress analysis}

The highest values in the contact pressure for each contact position were obtained to investigate the contact stress obtained from the simulation, as shown in Fig. 2. Figure 2 shows the contact pressure results corresponding to one mesh cycle between a pair of gear teeth for each COF. At zero friction, the calculated contact pressure is symmetrical with respect to the pitch point, and the maximum contact pressure is $187.7 \mathrm{MPa}$. The contact pressure is observed to be high near the pitch point, which 
is attributed to the change in the number of contact pairs. As shown in Fig. 3(a), the contact load is carried by a pair of gear teeth between the lowest point of single tooth contact (LPSTC) and the highest point of single tooth contact (HPSTC) or by two pairs of gear teeth. $\sigma_{H}$ at the pitch point calculated by AGMA and ISO 6336 is approximately 184.3 and $163.8 \mathrm{MPa}$, respectively. The contact stress calculated from ISO 6336 shows a $12.7 \%$ difference compared to the simulation result. However, the result from AGMA has an error of $1.8 \%$, which is in good agreement with the FEM results.

Friction has significant effects on the contact pressure. The maximum contact pressure values near the pitch point are 191.5, 199.5, and $209 \mathrm{MPa}$ for COFs of $0.1,0.3$, and 0.5 , respectively. The contact pressure along the mesh cycle exhibits the opposite behavior before and after the pitch point (Fig. 2). From the start of the contact to the pitch point, the contact pressure shifts upward as the COF increases. However, the contact pressure decreases rapidly after the pitch point until the end of the contact. It

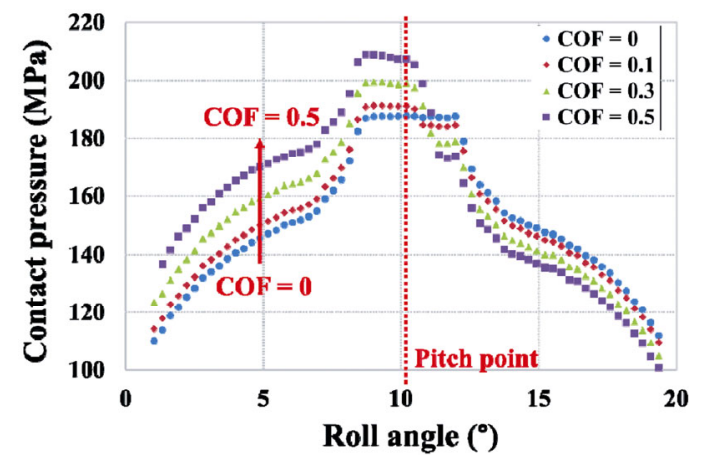

Fig. 2 Highest contact pressure values in each contact position with respect to COFs for a pair of bare gear teeth.

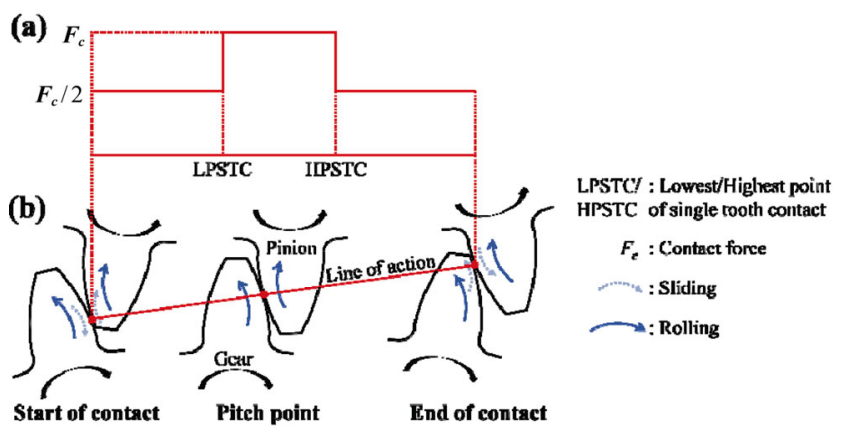

Fig. 3 Contact behavior of the involute spur gear: (a) distribution of the contact force along the line of action and (b) the rolling-sliding contact. Reproduced with permission from Ref. [37], (c) Elsevier B.V. 1998. should be noted that the contact pressure value after the pitch point is even lower than that in the case of zero friction. The behavior might be explained by the direction of the friction force induced by the sliding contact. The contact behavior of the involute spur gears consists of rolling and sliding contacts over the tooth flanks except at the pitch point, where only a rolling contact is present [37]. Figure 3(b) shows the contact behavior of the involute spur gears during rotation. As the driving gear tooth starts to engage with the pinion gear tooth, rolling and sliding contacts occur, and the directions of rolling and sliding are opposite to each other. However, as the teeth disengage, the directions of rolling and sliding are the same. A free-body diagram was constructed to understand the effect of the direction of the friction force induced by the sliding contact on the contact pressure, as shown in Fig. 4. $F_{\mathrm{f}}$ represents a friction force vector induced by the sliding contact. It can be decomposed into $F_{1}$ and $F_{2}$. Before the pitch point, as shown in Fig. 4(a), a torque is generated by $F_{1}$ that is in the direction opposite to the rotation of the driving gear. The torque interferes with the rotation of the driving gear, requiring more torque to rotate. Therefore, the contact pressure increases. After the pitch point, if the $F_{1}$ vector that is decomposed from $F_{\mathrm{f}}$ is taken into consideration, as shown in Fig. 4(b), it has the same direction as the driving gear. Consequently, the driving gear needs less torque to rotate than the constant load applied at the pinion gear, and thereby reducing the contact pressure after the pitch point.

Figure 5 shows the contact pressure results for coated polymer gears with respect to COFs. The maximum values near the pitch point are 190.1, 191.8, 193.5, and 195.3, MPa for COFs of 0, 0.05, 0.1,

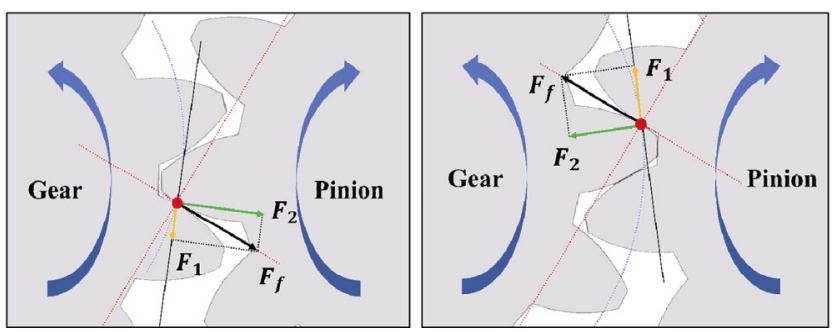

Fig. 4 Free-body diagram of the gear set (a) before and (b) after the pitch point. 


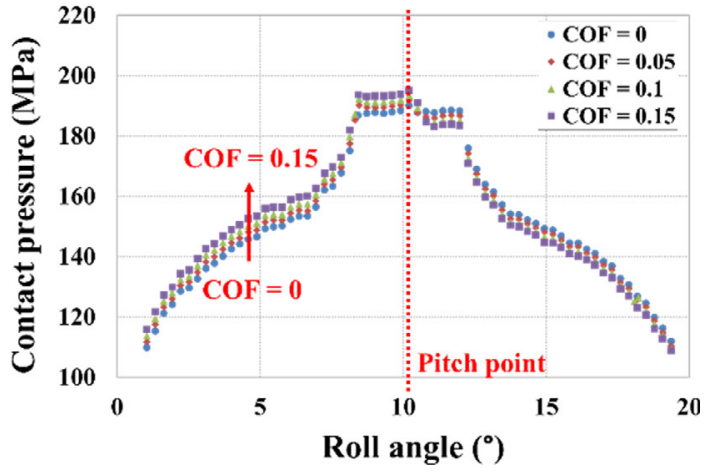

Fig. 5 Highest contact pressure values in each contact position with respect to the COF for a pair of coated gear teeth.

and 0.15 , respectively. With increasing friction, the contact pressure results exhibit a tendency similar to that of bare polymer gears. However, the presence of a coating on the polymer gear did not significantly affect the contact pressure. We postulate that a coating thickness of $2 \mu \mathrm{m}$ was too thin to affect the bulk deformation behavior of polymer gears, although the elastic modulus of the coating is much higher than that of the polymer gears.

\subsection{Stress analysis in the coating}

Stress analysis was performed for the moment, the contact point of the gear passes the pitch point to investigate the state of the stress within the coating, as shown in Fig. 6(a). The von Mises stress is displayed to evaluate the state of the stress in the coating at zero friction. Figure 6(b) shows an enlarged view of the stress distribution in the coating on the driving gear flank. There were three notable stress regions: (1) the center of the surface, (2) the end of the contact, and (3) the overall contact area. According to the Hertzian contact theory, the contact pressure of a non-conformal contact shows a parabolic distribution [26]. Similarly, two involute gear teeth in contact at the pitch point experience a curved shape of contact pressure distribution, resulting in the maximum value of $125.3 \mathrm{MPa}$ observed at the center of the contact surface. As a result of the contact, a flat contact area forms, which simultaneously leads to two stress regions. The first is the stress generated by bending. The coating is bent at the end of contact during the formation of the flat contact area. As shown in Fig. 7(c) at zero friction, bending produces tensile and compressive stresses within the coating near the end of the contact, which corresponds to the stress region in (2) in Fig. 6(b).

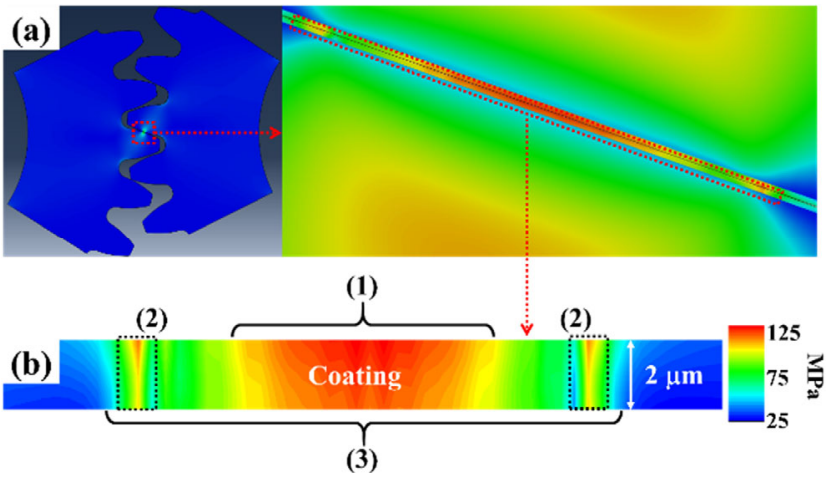

Fig. 6 Von Mises stress distribution of the gear set (a) at the pitch point and (b) of the coating with an enlarged view. In the enlarged view, three notable stress regions were found: (1) the center of the surface, (2) the end of contact, and (3) the overall contact area.

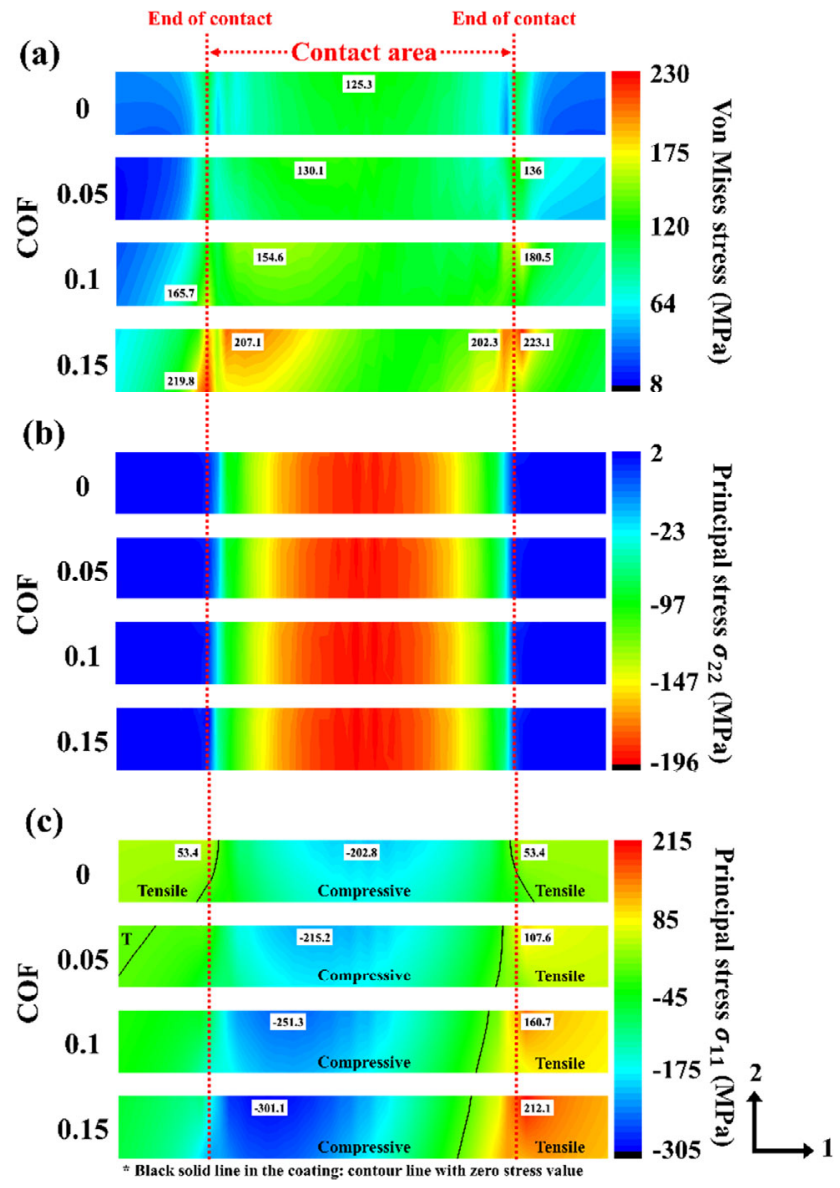

Fig. 7 Stress distribution of the coating at the pitch point with various COFs: (a) von Mises stress, (b) principal stress in the normal, and (c) tangential directions ( 1 and 2 in the coordinate system represent tangential and normal directions with respect to the contact area of the coating at the pitch point). 
The second is the overall compressive stress within the contact area. As the two gears come into contact, the surface that consists of the involute curve is compressed over the contact area. Hence, the original configuration of the curve is deformed, and this effect contributes to additional compressive stress within the contact area, as shown in (3) of Fig. 6(b).

Figure 7(a) shows the stress distribution in the coating at the pitch point with respect to COFs. As the COF increases to $0.05,0.1$, and 0.15 , the maximum von Mises stress values are 136, 180.5, and 223.1 $\mathrm{MPa}$, respectively. The maximum stress point is shifted from the center to the edges of the contact area as the friction increases. The stress distributions in Fig. 7(a) can be explained by the micro-slip that occurs during rolling. The contact at the pitch point is dominated by rolling, as shown in Fig. 3(b). During rolling with a given load, micro-slip occurs, generating a friction force in the tangential direction to the contact interface [38]. The principal stress distributions in both normal and tangential directions are displayed to clarify the effect of the micro-slip. As shown in Fig. 7(b), there is almost no change in the principal stress in the normal direction with increasing the COF. However, the principal stress in the tangential direction varies significantly with the COF. As shown in Fig. 7(c), the maximum compressive stress values increase to 202.8, 215.2, 251.3, and 301.1 MPa when the COF increases. The maximum tensile stress values of 53.4, 107.6, 160.7, and $212.1 \mathrm{MPa}$ are observed outside of the contact area when the COF increases.

Furthermore, there is no change in the contact area when the COF increases, as shown in Fig. 7. As described in Section 4.1, the driving torque increases before the pitch point and decreases after the pitch point because of the direction of the sliding friction. However, at the pitch point, the driving and the loading torque are the same because the rolling contact with no relative motion occurs at the pitch point, which means that the same normal stress is applied on the gears when the COF increases, resulting in a constant contact area.

\section{Conclusions}

In this study, a FEM was developed to investigate the contact stress of coated polymer gears. The model described the operation between a pair of gear teeth during a complete mesh cycle. Several COFs were added to the contact condition to analyze the contact stress over the roll angle. Moreover, an analysis of the stress in the coating was performed at the pitch point. Based on the results of the simulation, the following conclusions were obtained:

1) AGMA provided acceptable accuracy to evaluate the contact stress at the pitch point under frictionless conditions. The error of the AGMA result was only $1.8 \%$ in comparison to the simulation result.

2) The contact stress analysis on a pair of gear teeth during a complete mesh cycle showed that the sliding friction had a significant effect on the contact stress. When COFs were applied, the contact stress increased before the contact point reached the pitch point but decreased after the pitch point. This was attributed to the change in the direction of the sliding friction.

3) A coating of $2 \mu \mathrm{m}$ thickness had a negligible effect on the contact stress during the mesh cycle because the thickness was insufficient to affect the bulk deformation behavior of the polymer gears.

4) The stress distribution within the coating showed specific regions of tensile and compressive stresses that were caused by micro-slip at the contact interface. Higher COFs led to an increase in the stress within the coating.

\section{Acknowledgements}

This study was supported by the National Research Foundation of Korea (NRF) grant funded by the Korea Government (MSIT) (No. 2019R1H1A2039657).

Open Access This article is licensed under a Creative Commons Attribution 4.0 International License, which permits use, sharing, adaptation, distribution and reproduction in any medium or format, as long as you give appropriate credit to the original author(s) and the source, provide a link to the Creative Commons licence, and indicate if changes 
were made.

The images or other third party material in this article are included in the article's Creative Commons licence, unless indicated otherwise in a credit line to the material. If material is not included in the article's Creative Commons licence and your intended use is not permitted by statutory regulation or exceeds the permitted use, you will need to obtain permission directly from the copyright holder.

To view a copy of this licence, visit http://creativecommons.org/licenses/by/4.0/.

\section{References}

[1] Holmberg K, Erdemir A. Influence of tribology on global energy consumption, costs and emissions. Friction 5(3): 263-284 (2017)

[2] Pyo D, Lim J M, Mun S, Yun S. Silver-nanowires coated pitch-tuned coiled polymer actuator for large contractile strain under light-loading. Int J Precis Eng Manuf 19(12): 1895-1900 (2018)

[3] Hwang G W, Kim J W, Cho J U. A study on the fracture behavior of CFRP specimen with bonding interface under Mode 1 fatigue load according to laminate angle. Int J Precis Eng Manuf 19(12): 1829-1836 (2018)

[4] Mao K. A new approach for polymer composite gear design. Wear 262(3-4): 432-441 (2007)

[5] Mao K, Langlois P, Hu Z, Alharbi K, Xu X, Milson M, Li W, Hooke C J, Chetwynd D. The wear and thermal mechanical contact behaviour of machine cut polymer gears. Wear 332-333: 822-826 (2015)

[6] Bravo A, Koffi D, Toubal L, Erchiqui F. Life and damage mode modeling applied to plastic gears. Eng Fail Anal 58: 113-133 (2015)

[7] Dearn K D, Hoskins T J, Petrov D G, Reynolds S C, Banks R. Applications of dry film lubricants for polymer gears. Wear 298-299: 99-108 (2013)

[8] Kalin M, Kupec A. The dominant effect of temperature on the fatigue behaviour of polymer gears. Wear 376377: 1339-1346 (2017)

[9] Mertens A J, Senthilvelan S. Durability of polymer gearpaired with steel gear manufactured by wire cut electric discharge machining and hobbing. Int $J$ Precis Eng Manuf 17(2): 181-188 (2016)

[10] Bae S M, Khadem M, Seo K J, Kim D E. Evaluation of tribological characteristics of diamond-like carbon (DLC) coated plastic gear. Tribol Lubric 35(1): 1-8 (2019)

[11] Liu H J, Liu H L, Zhu C C, Wei P T, Tang J Y. Tribological behavior of coated spur gear pairs with tooth surface roughness. Friction 7(2): 117-128 (2019)

[12] Hoskins T J, Dearn K D, Chen Y K, Kukureka S N. The wear of PEEK in rolling-sliding contact-simulation of polymer gear applications. Wear 309(1-2): 35-42 (2014)

[13] Martinez-Martinez D, De Hosson J T M. On the deposition and properties of DLC protective coatings on elastomers: A critical review. Surf Coat Technol 258: 677-690 (2014)

[14] Khadem M, Penkov O V, Yang H K, Kim D E. Tribology of multilayer coatings for wear reduction: A review. Friction 5(3): 248-262 (2017)

[15] Penkov O V, Devizenko A Y, Khadem M, Zubarev E N, Kondratenko V V, Kim D E. Toward zero micro/macroscale wear using periodic nano-layered coatings. ACS Appl Mater Interfaces 7(32): 18136-18144 (2015)

[16] Khadem M, Park T L, Penkov O V, Kim D E. Highly transparent micro-patterned protective coatings on polyethylene terephthalate for flexible solar cell applications. Sol Energy 171: 629-637 (2018)

[17] Dufils J, Faverjon F, Héau C, Donnet C, Benayoun S, Valette $\mathrm{S}$. Evaluation of a variety of a-C:H coatings on PEEK for biomedical implants. Surf Coat Technol 313: 96-106 (2017)

[18] Erdemir A, Donnet C. Tribology of diamond-like carbon films: Recent progress and future prospects. $J$ Phys D: Appl Phys 39(18): R311-R327 (2006)

[19] Kalin M, Vižintin J. The tribological performance of DLC-coated gears lubricated with biodegradable oil in various pinion/gear material combinations. Wear 259 (7-12): 1270-1280 (2005)

[20] Dearnaley G, Arps J H. Biomedical applications of diamond-like carbon (DLC) coatings: A review. Surf Coat Technol 200(7): 2518-2524 (2005)

[21] Xie D, Liu H J, Deng X R, Leng Y X, Huang N. Deposition of a-C:H films on UHMWPE substrate and its wear-resistance. Appl Surf Sci 256(1): 284-288 (2009)

[22] Kot M. Contact mechanics of coating-substrate systems: Monolayer and multilayer coatings. Arch Civil Mech Eng 12(4): 464-470 (2012)

[23] Qin Z, Wu Y T, Lyu S K. A review of recent advances in design optimization of gearbox. Int J Precis Eng Manuf 19(11): 1753-1762 (2018)

[24] Patil S S, Karuppanan S, Atanasovska I, Wahab A A. Contact stress analysis of helical gear pairs, including frictional coefficients. Int J Mech Sci 85: 205-211 (2014)

[25] Karimpour M, Dearn K D, Walton D. A kinematic analysis of meshing polymer gear teeth. Proc Inst Mech Eng, Part L: J Mater: Des Appl 224(3): 101-115 (2010)

[26] Zhan J X, Fard M, Jazar R. A quasi-static FEM for estimating gear load capacity. Measurement 75: 40-49 (2015)

[27] Sfakiotakis V G, Vaitsis J P, Anifantis N K. Numerical simulation of conjugate spur gear action. Comput Struct 79(12): 1153-1160 (2001)

[28] Holmberg K, Ronkainen H, Laukkanen A, Wallin K, Erdemir A, Eryilmaz O. Tribological analysis of TiN and 
DLC coated contacts by 3D FEM modelling and stress simulation. Wear 264(9-10): 877-884 (2008)

[29] Chae Y, Chae G S, Youn Y O, Woo S, Shin S H, Lee J. Optimal design of thickness and Young's modulus of multi-layered foldable structure considering bending stress, neutral plane and delamination under $2.5 \mathrm{~mm}$ radius of curvature. Int $J$ Precis Eng Manuf 19(8): 1143-1154 (2018)

[30] Farley J, Wrobel L C, Mao K. Performance evaluation of multilayer thin film coatings under mixed rollingsliding dry contact conditions. Wear 268(1-2): 269-276 (2010)

[31] Trobentar B, Glodež S, Flašker J, Zafošnik B. The influence of surface coatings on the tooth tip deflection of polymer gears. Mater Tehnol 50(4): 517-522 (2016)

[32] Zhou C J, Li Z D, Hu B, Zhan H F, Han X. Analytical solution to bending and contact strength of spiral bevel gears in consideration of friction. Int J Mech Sci 128129: 475-485 (2017)

[33] Karsli N G, Demirkol S, Yilmaz T. Thermal aging and

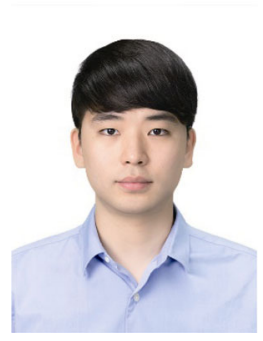

Su-Min BAE. He received his B.S. degree in mechanical and automotive engineering from Keimyung University, Seoul, Republic of Korea, in 2016. After then, he joined

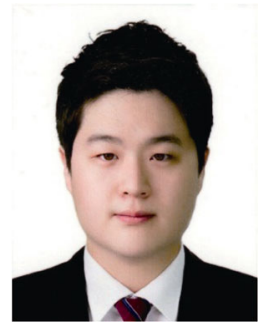

Kuk-Jin SEO. He received his B.S. degree in the Department of Mechanical Engineering from Yonsei University, Seoul, Republic of Korea,

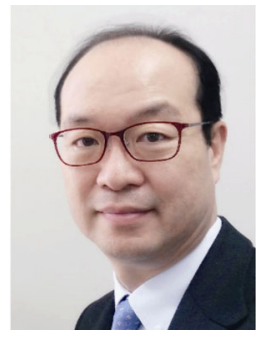

Dae-Eun KIM. He is a professor at the School of Mechanical Engineering at Yonsei University, Seoul, Republic of Korea. Prof. KIM received his B.S. from Tufts University, and M.S. and Ph.D. from Massachu-setts Institute of Technology. He was an assistant professor at the Ohio State University before joining Yonsei University in 1993. Prof. KIM is currently the president of the Korean Society for Precision Engineering, vice president of the International Tribology Council, reinforcement type effects on the tribological, thermal, thermomechanical, physical and morphological properties of poly(ether ether ketone) composites. Compos Part B: Eng 88: 253-263 (2016)

[34] Yao N, Evans A G, Cooper C V. Wear mechanism operating in W-DLC coatings in contact with machined steel surfaces. Surf Coat Technol 179(2-3): 306-313 (2004)

[35] Moorthy V, Shaw B A. Contact fatigue performance of helical gears with surface coatings. Wear 276-277: 130-140 (2012)

[36] Kaczorowski W, Szymanski W, Batory D, Niedzielski P. Tribological properties and characterization of diamond like carbon coatings deposited by $\mathrm{MW} / \mathrm{RF}$ and $\mathrm{RF}$ plasma-enhanced CVD method on poly(ether-etherketone). Plasma Processes Polym 11(9): 878-887 (2014)

[37] Walton D, Goodwin A J. The wear of unlubricated metallic spur gears. Wear 222(2): 103-113 (1998)

[38] Straffelini G. Friction and Wear: Methodologies for Design and Control. Cham (Switzerland): Springer, 2015.

the Center for Nano Wear (CNW) and obtained his M.S. degree from Yonsei University in 2019. His research interests include tribology, polymeric materials, diamond-like carbon, and finite element simulation.

in 2014. Currently, he is a Ph.D. candidate at the same university. His research interests include nanostructured and multi-layer coating with experimental and computational studies.

and vice president of the Asian Tribology Council. He has also served as the president of the Korean Tribology Society, Chair of the Tribology Technical Committee of IFToMM, editor-in-chief of IJPEM, senior editor of JMST, and associate editor of ASME J. of Tribology. Prof. KIM currently serves in the editorial board of Tribology Letter, Advances in Tribology, Friction, Frontiers in mechanical engineering, IJPEM-GT, and Tribology Online. Prof. KIM's research interests are tribology, coatings, and micro-fabrication. 